\title{
ANÁLISE DE ASPECTOS RELACIONADOS À APRENDIZAGEM EM UM CURSO À DISTÂNCIA ${ }^{1}$
}

\section{ANALYSIS OF ISSUES RELATED TO LEARNING AT A DISTANCE COURSE}

\author{
Lisiane Quadrado Closs ${ }^{2}$ \\ Vania Bessi ${ }^{3}$ \\ Juliane Aramburu ${ }^{4}$ \\ Roberto Lima Ruas ${ }^{5}$
}

\begin{abstract}
RESUMO: O artigo analisa aspectos relacionados à aprendizagem individual em um curso de Especialização em Gestão de Negócios Financeiros, realizado pela modalidade de ensino à distância, desenvolvido por uma universidade federal. $\mathrm{O}$ curso foi contratado por uma instituição financeira de âmbito nacional para capacitar futuros gestores. A análise desenvolvida privilegiou a primeira disciplina do curso, denominada Responsabilidade Sócio-Ambiental e concentrou-se em 3 de um total de 20 turmas que participam do programa, localizadas em Porto Alegre (RS), Londrina e Pato Branco (PR). Utilizaram-se, para a análise, os conteúdos das manifestações virtuais de alunos registradas nos diferentes canais disponibilizados como recursos pedagógicos: fóruns, chats e cafés virtuais. Buscou-se a sistematização de elementos que favorecem ou dificultam a aprendizagem entre os alunos. Os resultados iluminam possibilidades e limites específicos do Ensino à Distância, no que se refere à problemática da aprendizagem.
\end{abstract}

PALAVRAS-CHAVE: aprendizagem; ensino à distância

ABSTRACT: The article examines issues related to individual learning in a Financial Business Management Specialization Course, held by means of distance learning, developed by a Federal University. The course was hired by a financial institution of national scope to develop future managers. The analysis focused on the first discipline of the program, called Social-Environmental Responsibility and concentrated in 3 of a total of 20 classes participating in the program, located in Porto Alegre (RS), Londrina and Pato Branco (PR). It was used for the analysis, the contents of virtual demonstrations of students registered in the various channels available as teaching resources: forums, chats and virtual cafes. The aim was to the systematization of elements that promote or hinder the learning among students. The results illuminate specific possibilities and limits of Distance Learning, regarding the problem of learning.

KEY WORDS: learning; distance learning

\footnotetext{
${ }^{1}$ Artigo publicado no EnEPQ - I Encontro de Ensino e Pesquisa em Administração e Contabilidade - Recife / PE - 21 a 23 de novembro de 2007.

Artigo Recebido em 17.10.2008. Revisado por pares em 20.10.2008. Recomendado em 17.11.2008 por Denise Del Pra Netto Machado (editora). Publicado em 15.12.2008.

Organização Responsável pelo periódico: Universidade regional de Blumenau - FURB - www.furb.br/rn

${ }^{2}$ Doutoranda do Programa de Pós-Graduação da Escola de Administração da Universidade Federal do Rio Grande do Sul - 1closs@,terra.com.br

${ }^{3}$ Universidade Federal do Rio Grande do Sul - vania.bessi@terra.com.br

${ }^{4}$ Universidade Federal do Rio Grande do Sul - jvaramburu@ea.ufrgs.br

${ }^{5}$ Universidade Federal do Rio Grande do Sul - rlruas@ea.ufrgs.br
} 


\section{INTRODUÇÃO}

O exercício da profissão de gestor exige a capacidade de conceber estratégias, identificar alternativas, resolver problemas e decidir sobre situações complexas, envolvendo variáveis econômicas, políticas, psicológicas, sociais e financeiras, simultaneamente (LIMA, 2003). A formação destes profissionais requer processos de ensino-aprendizagem que possam prepará-los para enfrentar tais responsabilidades e desafios, explorados em diferentes abordagens e enfoques (NICOLINI, 2003; RUAS; 2003; MINTZBERG, 2005).

Alguns desses desafios têm sido tratados por meio de novas tecnologias de informação e comunicação nos processos de ensino-aprendizagem, a fim de transformar as tradicionais relações entre aluno, professor e conteúdo de aprendizagem, revolucionando os modos de ensinar e aprender. Entre as principais responsabilidades das instituições de ensino, hoje, está o aproveitamento dessas novas potencialidades, adequando os processos de ensinoaprendizagem ao contexto de desenvolvimento tecnológico atual (MARTÍ, 2001). Uma das mudanças mais importantes nesse campo é a dos sistemas de Educação à Distância (EAD), mediado pela Tecnologia de Comunicação Digital, capaz de disponibilizar condições para interação entre os seus atores (professores, alunos e outros atuadores) em tempo e espaço simultâneo, de forma síncrona ou assíncrona.

Dada a importância dos sistemas de EAD e a crescente demanda por aprendizagens exigidas de gestores atualmente, este artigo procura analisar elementos que favorecem ou dificultam a aprendizagem individual em um curso organizado nesta modalidade. $\mathrm{O}$ estudo enfoca as manifestações virtuais dos alunos de três turmas, dentre as vinte de um curso de Especialização em Gestão de Negócios Financeiros contratado a uma universidade federal por uma instituição financeira de âmbito nacional. As turmas analisadas, sediadas em três cidades da região sul, foram selecionadas por terem um número de alunos semelhantes. Contemplouse, para a análise, as manifestações virtuais dos alunos, sob a forma de interação entre eles e seus professores e/ou tutores, e entre os próprios alunos, nos recursos pedagógicos disponibilizados: fóruns, chats, cafés virtuais, aulas interativas e outros meios virtuais.

O artigo estrutura-se da seguinte forma: a seção dois apresenta uma breve revisão da literatura contemplando a orientação construtivista adotada pelo estudo, processos de ensinoaprendizagem envolvendo novas tecnologias e e-learning. A seção três traz considerações sobre o curso analisado. A quarta, apresenta e debate os aspectos relacionados à aprendizagem resultantes da realização da disciplina. Por último, as considerações finais do estudo.

\section{REFERENCIAL TEÓRICO: A PROBLEMÁTICA DA RELAÇÃO ENSINO- APRENDIZAGEM}

Cabe esclarecer, primeiramente, que o estudo aborda a aprendizagem sob o enfoque da epistemologia construtivista. Segundo Piaget (1896-1980), um dos principais expoentes do construtivismo, a inteligência, ou as estruturas cognitivas, não provém nem da bagagem hereditária nem do meio físico e social, provém de uma construção produzida pela ação do sujeito. O conhecimento se origina e se desenvolve por interação; os meios físico e/ou social disponibilizam uma série de informações que são assimiladas pelo sujeito ativo e acomodadas através do processo de auto-regulação do indivíduo; os indivíduos transformam os objetos e são transformados pelos desafios provindos dos mesmos. Aprender, nesse sentido, seria construir modelos para interpretar as informações recebidas (BECKER, 2001). De acordo com esta abordagem, além de ensinar, o professor deveria aprender o que o aluno já construiu até o momento, uma vez que os alunos utilizam-se de conhecimentos prévios para dar significado aos conteúdos e para (re)construir novos conhecimentos; as tarefas de 
aprendizagem deveriam desafiar os alunos, incentivando a formulação de perguntas ao invés da reprodução de respostas pré-existentes (BECKER, 2001).

\subsection{Novas tecnologias e processos de ensino-aprendizagem}

A partir de uma visão construtivista, Martí (2001) propõe que os processos de ensinoaprendizagem, utilizando as novas tecnologias, devem incluir, além das tradicionais relações entre aluno, professor e conteúdo de aprendizagem, a relação aluno-aluno e a introdução das novas tecnologias (entre elas o computador) como elemento mediador.

$\mathrm{Na}$ relação professor - novas tecnologias - conteúdo de aprendizagem, enfatiza-se a possibilidade de um ritmo de trabalho mais adaptado a cada aluno e a colaboração entre alunos para a realização de trabalhos, tornando possível um rompimento com conteúdos curriculares uniformes. A necessidade de adquirir os mesmo conteúdos de um currículo faz com que estudantes não consigam dominar determinadas partes, tendo que concentrar esforços em aspectos que possuem maior debilidade e não nos que se destacam. As redes de comunicação oportunizam que diferentes alunos possam especializar-se em diferentes aspectos de um mesmo projeto, diversificando os conteúdos de aprendizagem.

A construção de conhecimentos por parte dos alunos demanda tempo, exigindo a participação ativa do aluno e do professor. Muitas aplicações didáticas mediadas por computador exigem esforços adicionais dos alunos até que se familiarizem com elas, por isso, programas de conhecimentos extensos tendem a fracassar na obtenção de aprendizagens significativas; a seleção de alguns conceitos e procedimentos importantes é mais valiosa do que um conteúdo extenso e superficial. Neste contexto, que permite um trabalho mais individualizado e organizado em torno de projetos, a avaliação tradicional (medição de conhecimentos mediante provas ao final do processo de ensino-aprendizagem), perde o sentido. A avaliação deveria ser formativa, realizada ao longo do curso para poder avaliar o esforço e progresso dos alunos.

Destaca-se na relação professor - novas tecnologias - aluno, que a iniciativa para estabelecer uma interação com o professor é do aluno, partindo pela própria utilização do computador. Assim, muda a relação entre professores e alunos, permitindo a adoção progressiva de dinâmicas de ensino em que o professor siga orientando/guiando a aprendizagem dos alunos, mas respeitando os ritmos individuais e estimulando maior iniciativa. Com as novas tecnologias, alguns alunos podem chegar a um nível de conhecimento sobre determinado assunto que supere o do professor, não sendo mais este o referencial exclusivo do saber. Rompe-se, assim, com a estrutura hierárquica do saber.

Um dos temores envolvendo a relação aluno - novas tecnologias - aluno é o do isolamento dos alunos no processo de ensino-aprendizagem. No entanto, a realidade contraria esta suspeita; o computador, por suas características, pode estimular o trabalho em colaboração, sendo um elemento eficaz para promover o diálogo entre alunos. Uma das vantagens da EAD, além de permitir contatar com contextos sociais variados, é a de possibilitar que os alunos reflitam sobre a sua própria aprendizagem. A dimensão temporal muda; como a resposta dos outros participantes não é imediata, cria-se um tempo de consulta, reflexão e exploração, o que favorece a aprendizagem.

\subsection{E-learning}

O Ensino à Distância (EAD) é uma possibilidade de se reunir pessoas em um processo de ensino-aprendizagem, neste caso, alunos e professores/tutores que estão separados geograficamente, em um ambiente virtual. Além dos programas de EAD que utilizam a rede de computadores, outros tipos também podem ser encontrados, como: cursos por correspondência, telecursos, entre outros (BASTOS, 2003). O e-learning, por sua vez, é o EAD que dispõe do uso de tecnologias de informação para oferecer soluções que ampliem o 
conhecimento e o desempenho dos participantes (ROSEMBERG, 2001). Neste modelo, a tecnologia ocupa papel essencial, sendo a Internet o instrumento que propicia, de forma mais eficaz, a sua execução. Nesses cursos, ministrados através de rede de computadores, a interação entre alunos e professores ou tutores pode se dar de diversas formas: e-mail, listas de discussão, fórum de debates, salas de bate-papo (chats), envio de arquivos de texto, imagens, sons, bem como realização de tarefas, individuais e/ou coletivas, formando comunidade de aprendizagem (BASTOS, 2003).

Uma vantagem que vem sendo considerada para a concepção de cursos de e-learning é o fato de este possibilitar que pessoas que estejam em lugares remotos tenham acesso a cursos que, se conduzidos de forma presencial, não teriam. Também possibilita a interação, on line, de pessoas de diferentes culturas e com diferentes problemas a resolver, o que pode possibilitar uma rica troca de informações. Para organizações que possuam ramificações em diferentes cidades e estados, permite que um maior número de funcionários possa ser qualificado, sem altos custos de deslocamento. Nesse sentido, surge o e-learning corporativo que, conforme Bastos (2003), reúne a interatividade da internet com a possibilidade de personalizar cursos segundo a necessidade das organizações, a capacidade e o conhecimento do grupo de funcionários, otimizando o treinamento e o tempo que os funcionários dispõem. Apesar dos benefícios que o e-learning pode trazer, no entanto, alguns aspectos precisam ser vislumbrados e analisados pelas organizações quando se propõem a empreender esse tipo de programa. Uma possibilidade que vem sendo experimentada pelas organizações com grande sucesso é a parceria com universidades e instituições de ensino especializadas que fornecem os programas, na forma de pacotes dentro das necessidades da organização.

Testa e Freitas (2002) mencionam alguns elementos que devem ser considerados quando a organização optar por desenvolver um programa de ensino a distância, baseado na tecnologia, sendo alguns deles: o processo de comunicação, os modelos pedagógicos a serem utilizados, os softwares que irão gerenciar o processo e o ambiente virtual de aprendizagem, os equipamentos (hardwares) que serão utilizados, o papel dos professores, dos tutores e da equipe técnica, os modos de avaliação, os aspectos financeiros, a confiabilidade, a legislação, a disciplina dos alunos participantes, dentre outros.

Em pesquisa que visava avaliar os fatores determinantes na gestão dos cursos à distância, Testa e Freitas (2002), a partir de entrevistas com especialistas no assunto, detectaram os elementos que mais preocupam os entrevistados na condução desse tipo de curso. Entre as categorias mais citadas aparecem duas com maior número de ocorrências:

- Estudantes: categoria subdividida em alguns elementos: disposição e disciplina para a EAD; sentimento de abandono e isolamento; mudança cultural e adaptação (do presencial para o virtual); identificação das suas necessidades e desejos;

- Modelo pedagógico: definições do projeto pedagógico, da estratégia de educação da organização e do design instrucional; desenvolvimento dos cursos contextualizados com a cultura; necessidade de evitar a mera transmissão de informações.

Algumas categorias que apareceram com menor freqüência, embora também se constituam em preocupações dos especialistas são: tecnologia; gerenciamento dos programas; capacitação do pessoal para trabalhar com esse tipo de programa (já que a EAD necessita de um tempo maior de dedicação); envolvimento da organização, dos professores e dos tutores; modelos de avaliação que reflitam a realidade dos cursos; a imagem e a credibilidade dos programas de EAD; a socialização dos alunos, prejudicada quando não acontecem encontros presenciais com freqüência.

O EAD é uma mudança no paradigma educacional vigente ainda hoje, onde elementos como o contato face-a-face, a presença física em horários e locais pré-determinados e, mesmo, a imagem do professor como principal responsável pelo processo ensino- 
aprendizagem, prevalecem. Na EAD os alunos têm um papel decisivo, uma vez que lhes são exigidos maior participação e maior disciplina. Dos professores ou tutores é exigida, também, uma maior dedicação em termos de tempo, além da capacitação para a condução das atividades. Neste tipo de programa o papel do professor muda para uma posição de facilitador e não de principal responsável pelo processo de ensino-aprendizagem (ROSEMBERG, 2001).

\section{CONSIDERAÇÕES SOBRE O CURSO ANALISADO}

O curso de Especialização em Gestão de Negócios Financeiros foi desenvolvido por uma universidade do Rio Grande do Sul, em conjunto com a Universidade Corporativa de um grande banco de varejo do Brasil. A concepção do curso atendeu aos interesses deste banco de ampliar a competência dos seus profissionais em termos de conhecimentos, habilidades e valores (relacionados à qualidade do trabalho, à ética do comportamento, à convivência participativa e solidária, além de outros atributos como a iniciativa e a criatividade) necessários para o desempenho do trabalho. O curso busca auxiliar na capacitação de profissionais interessados em desenvolver carreira como gestores de agência, sendo estruturado de forma a colocar os participantes em contato com o que vem sendo considerado como mais moderno nas áreas de gestão bancária, objetivando dar aos pós-graduandos ferramentas de gestão para desenvolvimento de competências gerenciais e diretivas, além de habilitação para atuação como gestores. O programa envolve três módulos: formação geral, formação profissional e módulo complementar, com uma carga horária total de 480 horas.

O curso foi pensado para ter como público-alvo funcionários que exercem diferentes funções no banco e bancos coligados - gerentes, escriturários e educadores corporativos. $\mathrm{O}$ motivo de ter sido pensado como um curso à distância é a incompatibilidade de horários dos participantes, a impossibilidade de estarem em sala de aula em horários regulares e a grande abrangência geográfica que teria em virtude de o banco possuir unidades em todo o país.

Os temas são tratados de forma prática e teórica, buscando dar condições para que os participantes do curso possam fazer reflexões e estabelecer uma visão especializada e integrada da administração financeira e banking. O objetivo do curso é: "formar profissionais especialistas em Gestão de Negócios Financeiros, com sólida formação humanística, que venham a compreender a administração de instituições de forma integrada, sistêmica e estratégica, interna e externamente, trabalhando no desenvolvimento da ética, da postura profissional, da cidadania e da responsabilidade socioambiental" (documentos sobre o curso).

O modelo de ensino-aprendizagem do curso baseia-se na tecnologia de ensino desenvolvido por módulos, na modalidade à distância, com encontros presenciais periódicos nas praças-sede para aferição do conhecimento adquirido em disciplinas de módulos ou submódulos anteriores e para a apresentação de disciplinas de módulos ou sub-módulos seguintes. É enfatizado o aprendizado de forma interativa, com ênfase no uso de materiais impressos e de materiais e recursos virtuais disponibilizados por CDs e da rede internet. $\mathrm{O}$ aluno é acompanhado por um processo de tutoria ativa que, aliada ao uso da tecnologia, permite o monitoramento direto do desempenho e do fluxo de atividades, facilitando a identificação de possíveis dificuldades de aprendizagem. O ambiente virtual de estudos é personalizado e disponível vinte e quatro horas, apoiado por servidores, redes e equipamentos, voltados especificamente ao curso. Os alunos contam com suporte por e-mails e outros espaços de trocas de informações para o esclarecimento de dúvidas acadêmicas e a solução de dificuldades técnicas relacionadas ao uso da plataforma de ensino-aprendizagem.

Os alunos dispõem permanentemente, para acesso de acordo com sua disponibilidade, dos seguintes recursos: textos produzidos pelos professores responsáveis pelas disciplinas; vídeo-aulas digitais, contendo explicações sucintas, gravadas pelos professores, sobre os conceitos básicos de cada aula; acervo com arquivos para download, links, referências 
bibliográficas, biblioteca de legislação; além de outros materiais considerados relevantes para cada uma das disciplinas.

A apreensão dos conteúdos pelos alunos é verificada de forma constante, através de instrumentos como: exercícios on-line (para verificação da assimilação dos conteúdos respondidos e enviados pelos alunos dentro de prazos estipulados); estudos de caso, onde os alunos são desafiados a tomar decisões, a propor soluções e a realizar análises sobre situações concretas a eles propostas; relatos (espaço virtual no qual cada participante pode relatar experiência profissional vivenciada ou pesquisada, relacionada com os temas das disciplinas).

A participação dos alunos é monitorada e avaliada. Os ambientes virtuais que servem para verificar a interatividade dos alunos são:

- enquetes: com a formulação de questões sobre temas administrativos e tópicos específicos das disciplinas dos cursos;

- fórum acadêmico: espaço específico para cada disciplina e turma de praça-sede, destinado ao aporte de contribuições teóricas e práticas relacionadas ao conteúdos das aulas, pelos alunos e pelos professores e/ou tutores;

- aulas interativas: discussões, em tempo real, sobre os conteúdos das aulas da semana, em dias e horários ajustados entre os alunos e seus respectivos tutores. Podem ser realizas com ou sem vídeo, apresentando conversações diretamente dos alunos com os respectivos tutores de turmas, bem como com os professores das disciplinas.

- fórum técnico: espaço específico para cada disciplina e turma de praça-sede, destinado ao relato de dificuldades no uso de recursos de hardware e software;

- café virtual: espaço específico para cada disciplina e turma de praça-sede, destinado à discussão de aspectos mais informais da disciplina, visando gerar um ambiente virtual mais descontraído;

- videoconferências: transmissão de palestras proferidas por gestores, professores ou especialistas convidados.

Para a verificação de aprendizagem, os alunos são submetidos a avaliações durante o desenvolvimento das disciplinas online, assim como ao final de cada módulo ou sub-módulo de disciplinas cursadas. Durante o desenvolvimento das disciplinas, estão previstos mecanismos de avaliação relacionados à participação nos respectivos fóruns gerais e chats (existem indicadores com o número de participação de cada aluno em cada ambiente virtual), assim como ao desempenho em atividades individuais e atividades em equipe.

\subsection{A disciplina e as turmas - aspectos metodológicos}

A disciplina analisada, de Responsabilidade sócio-ambiental, tem uma carga horária de 30 horas e foi a primeira a ocorrer no curso, sendo precedida de um workshop presencial. Esta disciplina foi selecionada por ter sido a única concluída até o momento da pesquisa, além de suscitar interesse por ser a primeira experiência em EAD da maioria dos participantes (professores, tutores e alunos), uma vez que se busca avaliar a participação de alunos em uma experiência diferenciada, a de realizar um curso à distância. Foram analisadas, no presente estudo, três turmas, indicadas pela coordenação do curso pela composição semelhante com relação ao número de alunos. As turmas analisadas possuem sede em Pato Branco (48 alunos), Londrina (49 alunos) e Porto Alegre (46 alunos), embora cada turma seja constituída por alunos de várias cidades, agrupados pela proximidade com as sedes.

Para a análise da participação dos alunos utilizou-se o conteúdo de suas manifestações nos diversos canais disponíveis, especialmente fóruns, chats e cafés virtuais, espaços mais utilizados pelas turmas. Foi também analisada a participação dos tutores e dos professores, já que alguns autores ressaltam a importância de que professores e facilitadores estejam bem preparados para atuar nesse tipo de curso (BASTOS, 2003; ROSEMBERG, 2001). 
Para acessar os conteúdos analisados, obteve-se autorização (senha de acesso ao sistema) junto ao Núcleo responsável pelo curso na Universidade. A partir deste acesso, todas as participações de alunos, tutores e professores, do início ao fim da disciplina, foram analisadas, com o objetivo de identificar elementos que pudessem dificultar ou favorecer o processo de ensino-aprendizagem e, consequentemente, a aprendizagem dos participantes.

\section{ANÁLISE DOS RESULTADOS}

Percebe-se, através das manifestações nos diferentes canais de interação entre atores do curso, especialmente na primeira semana, uma dificuldade relacionada a problemas tecnológicos do programa de EAD: falhas no acesso (por sobrecarga do sistema), dificuldades para fazer downloads de vídeos, enviar trabalhos, dentre outros. Estes aspectos, relacionados à tecnologia e ao gerenciamento de programas, destacados entre os fatores determinantes na gestão de EAD por Testa e Freitas (2002), concentraram boa parte da atenção tanto de alunos, como de professores, tutores e coordenadores do curso, desviando o foco da disciplina e tornando-se um obstáculo inicial (solucionado no decorrer do curso) para o ensinoaprendizagem.

Uma segunda dificuldade inicial refere-se à aprendizagem da própria dinâmica do curso, já que esta foi a primeira incursão em EAD para muitos dos alunos, professores e tutores. Surgiram muitas dúvidas sobre como participar nas aulas interativas e no fórum, partindo dos próprios objetivos das interações entre outras tantas questões, exemplificadas pelo depoimento de um aluno: "gostaria de entender melhor a sistemática. [...] Temos que estudar o conteúdo do CD e participar dos chats, é isto? Estou um tanto quanto confuso...”. De acordo com outro relato, "Esta primeira semana foi de aprendizado tanto de conteúdo da matéria, mas principalmente desta metodologia de ensino. Espero que no próximo módulo consiga estar mais familiarizado. Confesso que estou 'apanhando' um pouco". Estas expressões corroboram a necessidade de um tempo maior de familiarização com as aplicações didáticas mediadas por computador antes do início das disciplinas (MARTÍ, 2001), a fim de que este aspecto não interfira nos objetivos de ensino-aprendizagem do programa.

A falta de familiarização com a sistemática do curso de EAD ficou clara em aspectos trazidos pelos alunos que mostravam, claramente, o paradigma da educação presencial. Verificam-se depoimentos que poderiam ser relacionadas ao ambiente de sala de aula, tais como a preocupação em acessar arquivos em horário determinado, a preocupação com o controle de presenças e, mesmo, a débil participação de alguns alunos nos canais disponibilizados, denotando a necessidade de uma mudança cultural e de uma adaptação dos alunos do ambiente presencial para o virtual (TESTA; FREITAS, 2002).

O ensino à distância ocasiona uma mudança da dimensão temporal (MARTÍ, 2001), oportunizando que os alunos assistam aos vídeos, releiam posteriormente os conteúdos das aulas interativas e organizem individualmente os horários dedicados ao curso. Surgiram, no entanto, obstáculos relacionados à disposição e à disciplina necessárias para muitos dos alunos realizarem estas tarefas, aspectos identificadas como essenciais para os alunos no EAD por Testa e Freitas (2002), já que a participação do aluno em um curso de EAD pode ser quantificada e é avaliada. Em um dos links disponibilizados no ambiente virtual eram apresentadas algumas tabelas com indicadores de participação dos alunos nos vários canais possíveis. Isso torna a participação ou a falta desta mais visível nessa dinâmica de ensinoaprendizagem, o que faz com que o aluno necessite desenvolver uma rotina de estudos e de participação nos canais. Muitos alunos, entretanto, relataram dificuldades na organização do tempo, sentindo-se "perdidos"; alguns outros assinalaram a sobrecarga de atividades.

Percebe-se, por outro lado, nas três turmas analisadas, que vários dos alunos aproveitaram o tempo de resposta não imediato de interação no fórum para realizar consultas a outras fontes de informações, explorar e refletir sobre os conteúdos, aspectos estes que 
favorecem a aprendizagem (MARTÍ, 2001). Isto é evidenciado por questionamentos, debates e reflexões, além da indicação de sites, livros, artigos, programas de TV, notícias e filmes registrados no fórum em torno da temática da disciplina. Conforme exemplificado pelo relato de uma aluna, "quando a gente começa a ter mais informações [...], a gente começa a se interessar sobre o assunto, começa a pesquisar, discutir, sugerir e participar". Nestas ocasiões, de acordo com a teoria construtivista, os alunos passam a exercer um papel ativo na construção de seus conhecimentos, havendo a verdadeira aprendizagem (BECKER, 2001).

É importante ressaltar que no EAD, tal como menciona Rosemberg (2001), o papel do professor ou tutor muda, passando a uma posição de facilitador. É necessário, como mencionam Testa e Freitas (2002), que esses atores estejam capacitados para atuar dentro de uma nova concepção de aprendizagem. $\mathrm{Na}$ análise das manifestações, no entanto, ficou claro que ainda falta, por parte de alguns tutores, uma maior aproximação com a metodologia do curso, além da conscientização de que esse tipo de atividade demanda um cuidado e um dispêndio de tempo maior, exigindo grande envolvimento com as turmas.

Este aspecto se evidenciou em vários momentos, em uma turma específica, onde os próprios alunos cobravam a participação mais ativa do tutor, como ilustra a fala de um dos alunos: "na outra turma, a tutora costuma colocar umas perguntas no fórum, para irem discutindo tópicos das matérias. [...] nosso fórum é uma mistura de café virtual e correio. Até costumo entrar com freqüência, mas vejo muitas perguntas e poucas respostas, algumas colocações e quase nenhum comentário". Nessa turma o processo de aprendizagem se deu muito a partir dos próprios alunos; a partir dessa manifestação, o grupo e o próprio tutor passam a participar mais, o que se constitui em um ganho para todo o grupo. Esta situação exemplifica o rompimento da estrutura hierárquica do saber proporcionada pelo processo de ensino-aprendizagem mediado por computador, bem como o aumento da responsabilidade dos alunos pela iniciativa para estabelecer interações com o professor/tutor (MARTÍ, 2001).

Torna-se também perceptível que não houve uma diretriz única de atuação por parte dos tutores. Em alguns momentos, especialmente no início do curso, transpareceram dúvidas em relação ao papel que eles deveriam desempenhar, tanto por parte dos alunos, como deles próprios. $\mathrm{Na}$ ausência de uma conduta explícita a ser seguida, possivelmente as intervenções dos tutores (e mesmo a ausência delas) tenham sido influenciadas por suas diferentes concepções epistemológicas sobre a aprendizagem, nem sempre voltadas para educar sujeitos ativos na produção de conhecimentos, conforme proposto por teorias de aprendizagem fundamentadas na epistemologia construtivista (BECKER, 2001).

Por outro lado, os tutores conseguiram desenvolver em duas das turmas analisadas, mesmo à distância, uma relação afetiva com os alunos. Esta relação pode favorecer a aprendizagem, já que a afetividade seria a energia, o que move a ação (PIAGET, 1962). Cabe salientar que a proximidade maior dos alunos se deu com os tutores porque estes tinham a incumbência de participar dos fóruns, chats, enviar e receber exercícios e relatos. Já a participação dos professores responsáveis pelas disciplinas restringiu-se às vídeo-aulas e a algumas aulas interativas, ficando um pouco mais distante do dia-a-dia dos estudantes.

Como a experiência em participar de cursos de EAD ainda não é algo corriqueiro, as dúvidas e dificuldades inerentes ao processo foram sendo resolvidas em conjunto, com a socialização no grande grupo. Isso permitiu que a interação entre os alunos e entre esses e os tutores ocorresse de forma mais próxima, ainda que à distância. Esta aproximação e a interação entre colegas ficaram visíveis nas manifestações ocorridas no café virtual, tido como um ambiente mais informal. Mesmo em um curso à distância, foi possível perceber o estabelecimento de vínculos de afeto entre colegas e entre aluno/tutor, sendo que em duas das turmas analisadas, os alunos foram explícitos em relatar a importância da participação/atuação dos tutores, reconhecendo e agradecendo pelo papel que estes exerceram no seu aprendizado. 
Percebe-se ainda que a oportunidade possibilitada pelo curso de socializar dúvidas e angústias em relação às atividades profissionais diárias dos alunos na instituição financeira favoreceu a ocorrência de aprendizagens, pois, quanto maior o autoconhecimento obtido através da interação com outros, permitindo feedback das próprias ações, maior a probabilidade de alcance dos resultados propostos pelo curso.

\section{CONSIDERAÇÕES FINAIS}

Pode-se verificar, ao final deste texto, que o método de análise dos dados adotado, embora pouco convencional, pode constituir um precioso instrumento de investigação de processos de aprendizagem em cursos do tipo EAD. A análise do conteúdo de manifestações de alunos e tutores pode representar, como demonstrado nesta pesquisa, um rico material de estudo quando se deseja verificar processos de aprendizagem em ambiência virtual.

Embora não sendo um objetivo do estudo, a leitura das diferentes intervenções de alunos e de tutores possibilitou visualizar que, além da própria aprendizagem individual, ocorreu uma aprendizagem coletiva envolvendo conhecimentos, habilidades e atitudes que, disseminando-se entre outros grupos e departamentos do banco, pode transformar-se em aprendizagem organizacional.

Visualiza-se um processo de aprendizagem ocorrendo na própria gestão do curso. A partir das demandas dos alunos e do desejo de ouvir e de fazer as adequações necessárias para facilitar os processos de ensino-aprendizagem do programa, foram ocorrendo mudanças da própria dinâmica da disciplina, tais como a flexibilização dos horários de participação nas atividades, a combinação de horários para a realização dos chats entre os tutores e alunos de cada turma, entre outras, possibilitadas pelas características inerentes à modalidade de EAD.

Sugere-se, para o desenvolvimento de futuros cursos à distância, a organização de um módulo inicial voltado para a familiarização de alunos, tutores e professores com o ambiente virtual, permitindo um tempo para o aprendizado da sistemática própria à $\mathrm{EAD}$, bem como ao uso de seus recursos. Desse modo, se evitaria o desvio dos objetivos de aprendizagem de disciplinas iniciais, como o ocorrido na experiência analisada pela pesquisa, indicada pelos relatos de vários alunos, especialmente na primeira semana de curso. Uma mudança do paradigma presencial para o virtual requer um processo de revisão de conceitos e crenças introjetados ao longo dos anos sobre o ensino-aprendizagem em sala de aula tanto por alunos como pelos professores/tutores. Esta mudança requer, em si, um processo de aprendizagem que necessita de um período de maturação.

Como observado neste trabalho, bem como em outros casos de EAD apresentados pela literatura, existem características específicas nesta modalidade de ensino. Estudos posteriores podem realizar um comparativo entre estas especificidades de cursos presenciais e à distância, destacando possibilidades e limitações para o processo de ensino-aprendizagem de cada uma destas modalidades. Um aprofundamento da compreensão dos aspectos diferenciais do processo de ensino-aprendizagem à distância iluminaria o desenvolvimento de futuros programas, contribuindo para o aprimoramento desta modalidade de ensino, bem como para a ampliação do conhecimento neste campo de estudos em Administração.

\section{REFERÊNCIAS}

BASTOS, L. Avaliação do E-learning corporativo no Brasil. Salvador: UFB. 2003.

BECKER, F. Educação e construção do conhecimento. Porto Alegre: Artmed, 2001. 
LIMA, M. C. Estudos de casos hipertextuais: rumo a uma inovação no método Harvard de ensino de gestão. Revista de Administração Contemporânea, v.7, n.3, jul.-set. 2003.

MINTZBERG, H. MBA, Não, Obrigado!; P.Alegre, Bookman, 2005

MOREIRA, M. A. Teorias de Aprendizagem, São Paulo: EPU, 1999.

NICOLINI, A. Qual será o futuro das fábricas de administradores? RAE, vol. 43, n. 2, p.44$54,2003$.

PIAGET, J. The relation of affetivity to intelligence in the mental development of the child. In Bulletin of the Menninger clinic. - 1962, vol. 26, no 3.

POZO, J. I. Aprendizes e mestres: a nova cultura da aprendizagem. Porto Alegre: Artmed Editora, 2002.

MARTÍ, E. Novas tecnologias e processos de ensino-aprendizagem. In: CARRASCO PONS, S. La ciudad como proyecto educativo. Barcelona: Edicions Octaedro S.L , 2001.

ROSEMBERG, M. E-Learning: estratégias para a transmissão do conhecimento na era digital. São Paulo : Makron Books. 2001.

RUAS, R. Mestrado Modalidade Profissional: em busca da identidade. $R A E$, vol.43, n. 2, p.55-63, 2003.

TESTA, M.; FREITAS, H. Fatores importantes na gestão de programas de educação à distância via Internet: a visão dos especialistas. In: ENANPAD, XXVI 2002, Campinas. Anais... Campinas, 2002. 1CD-Rom. 